\title{
SARAMPO: CUSTO DA HOSPITALIZAÇÃO E VACINAÇÃO NA REGIĀO DE LONDRINA - PARANÁ
}

\author{
Elma Mathias Dessunti* \\ Angela Alencar Araripe Façanha* \\ Marcia Maria Benevenuto de Oliveira* \\ Margareth Faiad Name Villari*
}

\begin{abstract}
RESUMO - O presente estudo se propõe a analisar os casos de sarampo na região de Londrina-PR, bem como verificar os custos de um paciente internado e os custos da vacina nas redes pública e particular. Os dados foram coletados junto ao Hospital Universitário Regional do Norte do Paraná, Secretaria Estadual de Saúde da Fundação Caetano Munhoz da Rocha e a uma clfnica particular, em janeiro de 1989. Concluiu-se que o sarampo continua sendo uma doença endêmica na região estudada, sendo que $11,9 \%$ de todos os casos necessitaram de internação hospitalar. Observou-se também que, com o custo de uma hospitalização, num perlodo de seis dias, seria possfvel imunizar 3144 crianças na rede pública e 94 crianças na rede particular.
\end{abstract}

ABSTRACT - The presente estudy aims to analyse measels cases in Londrina-PR, as well as to verify the costs of an interned patient and the costs of the vaccin in public health centers and private clinics. The data was collected at University Regional Hospital of Northen Paraná, Health State Secretary of Caetano Munhoz da Rocha Foundation and at a private Clinic, in January, 1989. It was concluded the measles is still and endemic disease in the Studied Region, having $11,9 \%$ of all cases need hospital internment. It was also observed that, considering the cost of one hospitalization in a period of six days, it would be possible to vaccinate 3144 children in public health centers and 94 children in private clinics.

\section{INTRODUÇÃO}

O sarampo $\varepsilon$ uma doença infecciosa aguda, de elevada contagiosidade, causada por virus e potencialmente grave quando acomete crianças desnutridas.

Caracteriza-se pelo aparecimento de um enantema patognomônico na mucosa bucal - manchas de Koplik - e por manifestações catarrais oculares e das vias respiratórias superiores, bem como por erupção máculo-papulosa típica da pele (BENENSON ${ }^{2}$, MORLE $Y^{10}$ ).

As complicações mais comumente observadas no sarampo atingem o ouvido médio, trato respiratório, sistema nervoso central, olhos e pele. Essas complicações podem ser uma consequência da multiplicação viral ou de super-infecção bacteriana e inclui: otite média, laringite, laringotraqueobronquite, pneumonia, bronquiolite, desidratação, encefalite aguda, penencefalite esclerosante subaguda, reativação de tuberculose lactente ou o agravamento de tuberculose em atividade, dentre outras (BENENSON ${ }^{2}$, MITRE , MORAES $^{*}$ ).

MORLEY ${ }^{10}$ destaca a interação entre nutrição $e$ infecção por sarampo, ou seja, quanto mais grave e maior a duração da infecção, pior o efeito sobre a nutrição da criança. Por outro lado, a desnutrição na criança leva a infecção mais grave e de maior duração.
Segundo MITRE, MORAES ${ }^{9}$ e MARTINS ${ }^{8}$, o sarampo é uma das doenças mais contagiosas, ocorrendo a transmissão em cerca de $90 \%$ dos contatos íntimos. Essa transmissão ocorre mais comumente pelo contato direto com as secreções nasofaríngeas, eliminadas por tosse ou espirro e com menor frequiência pelo contato indireto (fômites).

O período de transmissibilidade se estende desde o início do período padrômico até quatro dias depois do aparecimento da erupção cutânea; a contagiosidade máxima ocorre no período catarral (BENENSON², MARTINS $\left.^{8}\right)$.

Praticamente todos os indivíduos que não tiveram a doença ou não foram imunizados são suscetíveis ao sarampo. Os lactentes cujas mães tiveram a doença, apresentam em geral imunidade até os primeiros 6 a 9 meses de vida. A doença geralmente confere imunidade permanente (BENENSON ${ }^{2}$ ).

A distribuição do sarampo é universal, não distinguindo raça ou sexo. Em países subdesenvolvidos, o sarampo predomina em crianças com até dois anos de idade e a desnutrição predispōe ao aparecimento de complicações, aumentando o indice de mortalidade.

A incidência do sarampo no Brasil é diff́cil de ser determinada, devido às dificuldades de notificação.

* Docentes do Departamento de Enfermagem do Centro de Ciências da Saúde da Universidade Estadual do Paraná. 
Um estudo realizado em São Paulo mostrou que. a incidência em 1982 estava em torno de 10,56 por 100.000 habitantes (ALMEIDA et alii ${ }^{1}$ ).

Alguns estudos têm demonstrado que a letalidade do sarampo é maior nos não vacinados e nas crianças de baixa idade e varia de 20 a $40 \%$ em regiões subdesenvolvidas. Através da Investigação Interamericana de Mortalidade na Infância, realizada em três cidades brasileiras, Recife, Ribeirão Preto e São Paulo, no período de 1968 a 1972, soube-se que o sarampo constituiu a principal causa de óbito não apenas entre as doenças infecciosas, mas entre todas as causas, nas crianças de 1 a 4 anos. Mostrou-se, ainda, que cerca de $60 \%$ dos obitos ocorreram em desnutridos (MARTINS $^{8}$ ).

Com a introdução do uso prático da vacina contendo vírus vivos atenuados, a incidência do sarampo sofreu, no início da década de 60 , diminuição acentuada nos países onde essa vacina passou a ser aplicada sistematicamente.

$\mathrm{O}$ número de doses varia de acordo com a idade; em países desenvolvidos aplica-se uma única dose da vacina aos 15 meses de vida. No Brasil, onde o sarampo atinge grande número de crianças de baixa idade e/ou desnutridas, o Ministério da Saúde preconiza a aplicação de uma dose da vacina no nono e outra no décimo quinto mês de idade. Em condições ịdeais de armazenamento, as vacinas empregadas induzem 0 aparecimento de anticorpos em 90 a $97 \%$ dos vacinados e persistem durante tempo prolongado em níveis protetores (MARTINS ${ }^{8}$, MITRE, MORAES ${ }^{9}$ ).

Nos Estados Unidos, onde tenta-se a erradicação da doença, o número de casos tem diminuído acentuadamente. No Brasil, a incidência do sarampo continua elevada, tendo sido notificados 30.995 casos em 1982; 55.179 em 1983; 77.650 em 1984; 75.993 em 1985 e 116.781 em 1986 (MITRE, MORAES $^{9}$ ).

No Estado do Paraná foram notificados 21.326 casos nos anos de 1986 a 1988, com 108 6́bitos (Fonte: Divisão de Vigilância Epidemiológica do Estado DECD/FCRM/SESA). Em Londrina-PR, foram internados 93 pacientes com diagnóstico de sarampo no mesmo período citado (Fonte: Livro de Registro de pacientes internados na Unidade de Doenças Transmissíveis do Hospital Universitário Regional do Norte do Parana).

Convém ressaltar que a assistência a esses pacientes deve ser prestada por equipe especializada, além de exigir local e ambiente que propiciam um tratamento adequado e eficiente. Os aspectos psicossociais de uma criança internada também devem ser considerados, além de algumas complicações que podem levar à sequielas.
Em decorrência do exposto acima é que o presente trabalho se propõe a analisar os casos de sarampo na região de Londrina, assim como verificar os custos de um paciente internado e os custos da vacina nas redes pública e particular.

\section{Objetivos}

- Levantar o número de casos de sarampo na região de Londrina, assim como o número de internações decorrentes desta doença.

- Comparar os custos da vacinação nas redes pública e particular, com os custos de um paciente internado com sarampo.

- Demonstrar aos órgãos públicos e aos profissionais da área de saúde, a situação real do sarampo em relação aos custos com hosvitalização e vacinação na região de Londrina.

\section{METODOLOGIA}

O estudo foi realizado no Hospital Universitário Regional do Norte do Parana (HURNP), situado em Londrina, por ser a única Instituição da região que dispõe de Unidade especializada para atendimento a pacientes portadores de doenças transmissíveis.

Os dados foram obtidos junto à Diretoria Administrativa - Seção de Custos e Orçamentos, junto ao SAME e Livro de Registro de Pacientes da Unidade de Doenças Transmissíveis (UDT).

Para o cálculo do número de dias de internação dos casos de sarampo, foi utlizado a média aritmética.

$\mathrm{O}$ custo do paciente-dia foi a unidade de gasto hospitalar, representando a média dos dispêndios diretos e indiretos por serviço prestado a um paciente, num dia hospitalar.

Os custos da vacina foram pesquisados através da Secretaria Estadual de Saúde (SESA), da Fundação Caetano Munhoz da Rocha e em uma clínica particular no Município de Londrina, relativo ao mês de janeiro de 1989.

A população foi constituída pela totalidade de casos de sarampo notificados ao 17음 Distrito Sanitário, em Londrina,no período de $1^{\circ}$ de janeiro de 1986 a 31 de dezembro de 1988.

\section{RESULTADOS}

Após análise e tabulação dos dados, chegou-se aos resultados apresentados a seguir:

TABELA 1 - Números em porcentagem dos casos de sarampo notificados ao 170 Distrito Sanitário nos anos de 1986 a 1988, por faixa etária. Londrina-PR.

\begin{tabular}{|c|c|c|c|c|c|c|c|c|c|}
\hline \multirow[b]{2}{*}{ Faixa Etária } & \multirow[t]{2}{*}{ Ano } & \multicolumn{2}{|c|}{1986} & \multicolumn{2}{|c|}{1987} & \multicolumn{2}{|c|}{1988} & \multicolumn{2}{|c|}{ Total } \\
\hline & & $\mathrm{n}^{\circ}$ & $\%$ & $\mathrm{n}^{\mathrm{O}}$ & $\%$ & $\mathrm{n}^{\mathrm{O}}$ & $\%$ & $n^{2}$ & $\%$ \\
\hline 5 a 11 meses & & 14 & 1,8 & 84 & 10,7 & 06 & 0,8 & 104 & 13,3 \\
\hline 1 a 4 anos & & 43 & 5,5 & 166 & 20,6 & 14 & 1,8 & 218 & 27,9 \\
\hline 5 a 9 anos & & 43 & 5,5 & 178 & 22,7 & 20 & 2,6 & 241 & 30,8 \\
\hline 10 a 14 anos & & 15 & 1,9 & 84 & 10,7 & 05 & 0,6 & 104 & 13,2 \\
\hline 15 anos e mais & & 11 & 1,4 & 102 & 13,0 & 03 & 0,4 & 116 & 14,8 \\
\hline Total & & 126 & 16,1 & 609 & 77,7 & 48 & 6,2 & 783 & 100,0 \\
\hline
\end{tabular}

FONTE: Secretaria de Saúde e de Bem-Estar Social do Estado do Paraná - DECD/FCMR/SESA. 
Observando-se a tabela acima pode-se constatar que $77,7 \%$ dos casos de sarampo notificados ao $17^{\circ}$ Distrito Sanitário de Londrina ocorreram no ano de 1987. Nota-se, ainda, que a maioria dos casos ocorreu na faixa etária de 5 a 9 anos $(30,8 \%)$ e na faixa de 1 a 4 anos (27,9\%).

Destaca-se, nesta tabela, a ocorrência de sarampo na faixa etária de 10 a 14 anos $(13,2 \%)$ e nos indivíduos com 15 anos e mais de idade $(14,8 \%)$.

TABELA 2 - Número e porcentagem dos casos de sarampo internados no HURNP, nos anos de 1986 a 1988 , por faixa etária - Londrina-PR.

\begin{tabular}{|c|c|c|c|c|c|c|c|c|c|}
\hline \multirow[b]{2}{*}{ Faixa Etária } & \multirow{2}{*}{ Ano } & \multicolumn{2}{|c|}{1986} & \multicolumn{2}{|c|}{1987} & \multicolumn{2}{|c|}{1988} & \multicolumn{2}{|c|}{ Total } \\
\hline & & no & $\%$ & no & $\%$ & n' & $\%$ & $\mathrm{n}^{\circ}$ & $\%$ \\
\hline 5 a 11 meses & & 02 & 2,1 & 20 & 21,5 & 01 & 1,1 & 23 & 24,7 \\
\hline 1 a 4 anos & & 06 & 6,5 & 27 & 29,0 & - & - & 33 & 35,5 \\
\hline 5 a 9 anos & & 01 & 1,1 & 07 & 7,5 & 01 & 1,1 & 09 & 9,7 \\
\hline 10 a 14 anos & & 03 & 3,2 & 08 & 8,6 & 01 & 1,1 & 12 & 12,9 \\
\hline 15 anos e mais & & 01 & 1,1 & 13 & 14,0 & 02 & 2,1 & 16 & 17,2 \\
\hline Total & & 13 & 14,0 & 75 & 80,6 & 05 & 5,4 & 93 & 100,0 \\
\hline
\end{tabular}

FONTE: Livro de Registro de pacientes internados na Unidade de Dcenças Transmissíveis do HURNP.

Pela tabela 2 pode-se verificar que $80,6 \%$ das internações por sarampo ocorreram no ano de 1987 . A faixa etária mais acometida foi de 1 a 4 anos $(35,5 \%)$ e de 5 a 11 meses $(24,7 \%)$, Observa-se ainda que $17,2 \%$ tinham 15 anos ou mais e $12,9 \%$ de 10 a 14 anos.

TABELA 3 - Comparação do número e porcentagem de casos de sarampo notificados e internados nos anos de 1986 a 1988 - Londrina-PR.

\begin{tabular}{|c|c|c|c|c|c|}
\hline No & 1986 & 1987 & 1988 & & \\
\hline № de Casos & n' & no & no & $\mathrm{n}^{\mathrm{O}}$ & $\%$ \\
\hline Notificados & 16,1 & 77,7 & 6,2 & 783 & 100,0 \\
\hline Internados & 1,7 & 9,6 & 0,6 & 93 & 11,9 \\
\hline
\end{tabular}

FONTE: Secretaria de Saúde e do Bem-Estar Social do Estado do Paraná - DECD/FCMR/SESA e Livro de registro de pacientes internados na Unidade de Doenças Transmissíveis no HURNP.

GRAFICO 1 - Custo da vacina e hospitalização por sarampo no mês de janeiro de 1989 em Londrina-PR.

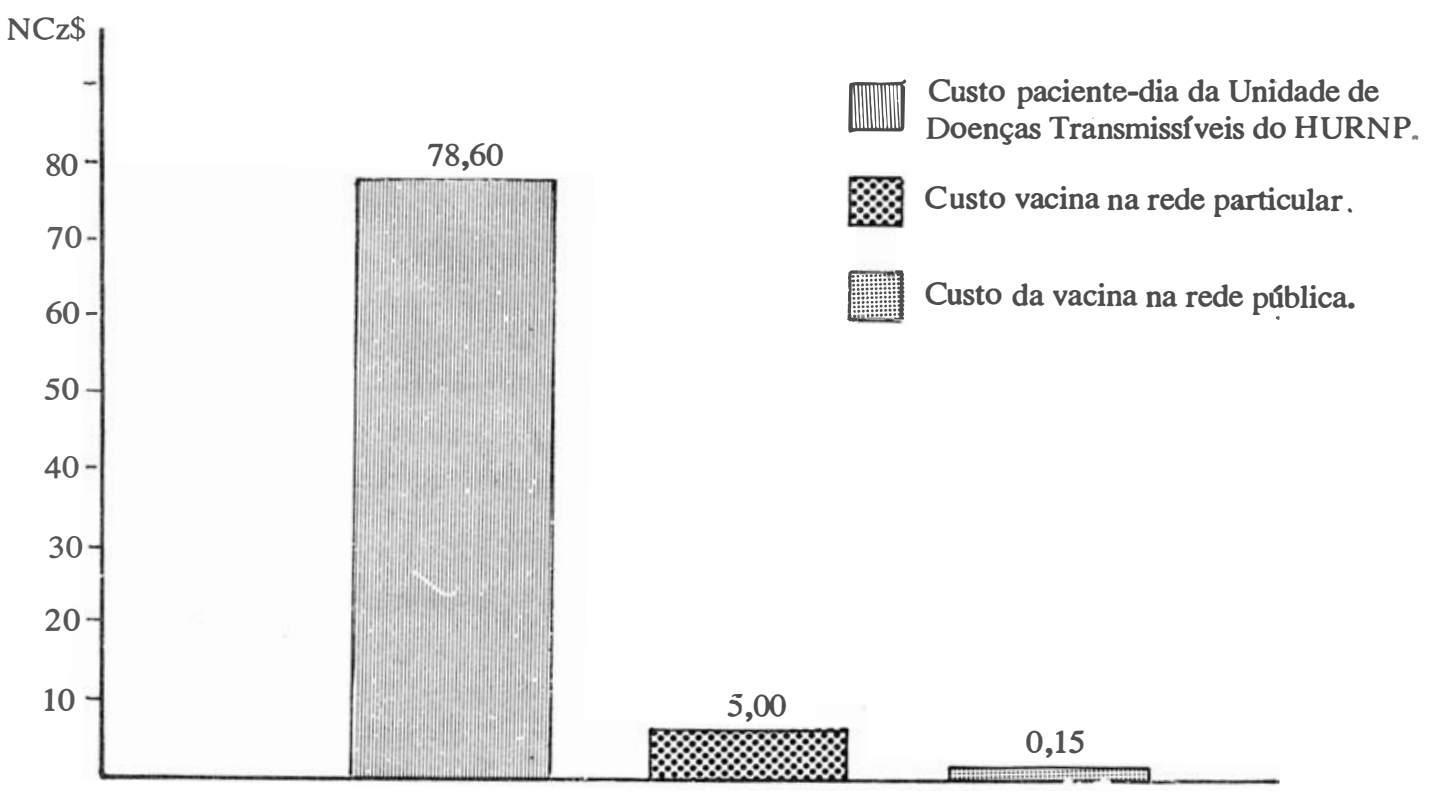

Fonte: Sec. de Estado da Saúde e do Bem-estar Social, Hospital Universitário Regional do Norte do Paraná e clínica particular de imunizações. 
Analisando-se a tabela 3 pode-se observar que do total de casos notificados nos anos de 1986 a 1988 (793) $11,9 \%$ nocessitaram de internação. Nota-se ainda, que a maioria das internações ocorreram no ano de 1987 (9,6\%), onde houve maior incidência da doença.

\section{DISCUSSĀO}

Neste estudo, verificou-se a incidência de sarampo, por faixa etária, no $17^{\circ}$ Distrito Sanitário, em Londrina, nos anos de 1986 a 1988. levantou-se, também, o número de casos internados neste período, assim como custos da hospitalização e da vacinação nas redes pública e particular.

A tabela 1 mostra que, dos 783 casos de sarampo notificados, $77,7 \%$ ocorreram no ano de 1987. Em relação à faixa etária, observa-se que a maior incidência ocorreu nas faixas etárias entre 5 a 9 anos $(30,8 \%)$ e entre 1 a 4 anos $(27,9 \%)$.

Comparando-se esses dados com os apresentados por MARTINS ${ }^{8}$, no Estado de São Paulo, a faixa etária mais acometida entre 1979-80, situa-se entre 1 a 4 anos $(42,4 \%)$, seguida da faixa etária de 5 a 9 anos $(21,1 \%)$ e entre 0 a 11 meses $(20,8 \%)$, observando-se que nas duas populações estudadas, a maior incidência do sarampo ocorreu em crianças com idade inferior a 10 anos.

ressalta-se ainda, na mesma tabela, a incidência da doença entre 10 a 14 anos $(13,2 \%)$ e nos indivíduos com 15 anos e mais $(14,8 \%)$.

Segundo o MINISTERIO DA SAÚDE4, numa investigação é epidemiológica realizada na vigéncia de um surto de sarampo, em Catalão - Goiás, verificouse que a maioria dos casos ocorreu em crianças entre 5 e 14 anos de idade.

Decorrente destas situações', é que o Ministério da Saúde, atualmente, recomenda que a vacina antisarampo se ja administrada até aos 14 anos de idade.

Analisando-se a tabela 2 pode-se constatar que das 93 internações ocorridas por sarampo nos casos de 1986 a 1988, 80,6\% ocorreram no ano de 1987, ano este, em que houve maior número de casos notificados. Desta-se., ainda, que os grupos etários que mais necessitaram de internação situam-se entre 1 a 4 anos $(35,5 \%)$ e entre si 5 a 11 meses $(24,7 \%)$.

Estudo semelhante realizado por RISI Jr. ${ }^{11}$ no Estado de São Paulo, no período de 1974 a 1980, indica 9.141 casos de internações por sarampo, dos quais $20,8 \%$ tinham menos de um ano de idade. Este mesmo estudo mostra que das 2.729 mortes anuais (em média) ocorridas no Brasil, no mesmo período, em doentes com sarampo, $41,6 \%$ ocorreram em crianças com menos de um ano.

Esses fatos indicam a necessidade da vacinação antes do primeiro ano de vida, que no caso do Brasil, é recomendada uma primeira dose aos nove meses de idade (MITRE \& MORAES $^{9}$ ).

Pela tabela 3 pode-se verificar que $11,9 \%$ dos 783 casos de sarampo notificados necessitaram de internação.

Segundo LEONARDI et alii ${ }^{7}$, muitos fatores são levados em consideração para se internar uma pessoa com sarampo; entre elas estão as complicações que podem advir, colocando em risco a vida do paciente. Outro motivo, citado pelas mesmas autoras, diz respeito ao nível socio-econômico do paciente e seus fa- miliares, com condições precárias de saneamento e higiene, favorecendo a transmissão da doença, além da desnutrição quase sempre presente.

O Grafico 1 demonstra os custos da vacina antisarampo na rede pública $(\mathrm{NCz} \$ 0,15)$ e particular (NCz\$ 5,00), além do custo paciente-dia na Unidade de Doenças Transmissíveis do HURNP $(\mathrm{NCz} \$ 78,60)$ no mês de janeiro de 1989.

Considerando-se a média de permanência do paciente internado com sarampo no HURNP, ou se ja, seis dias, a Instituição terá cerca de $\mathrm{NCz} \$ 471,60$ de despesa com hospitalização.

Comparando-se esses custos com o custo da vacinação na rede pública e particular, percebe-se o quanto é oneroso uma internação por sarampo, além dos aspectos psico-s6cio-culturais que tamberm devem ser considerados durante a hospitalização.

Para exemplificar, seria possível imunizar, aproximadamente, 524 crianças com a vacina anti-sarampo na rede pública e 16 crianças na rede particular, com um dia de internação decorrente da mesma patologia. Se consideramos a média de permanência de seis dias, esses números passariam para 3.144 e 94، crianças, respectivamente. destaca-se, ainda, que o custo da anti-sarampo na rede particular é 33,3 vezes maior que o custo da mesma vacina na rede pública.

Trabalho semelhante realizado por LEONARDI et alii ${ }^{7}$ indica tamberm o quanto é dispendidos manter um doente contagioso no hospital e o quanto é suave, financeiramente, a prevenção da doença, através da vacinação.

O controle do sarampo pode ser obtido através de um programa muito eficiente de vacinação, devido à repidez com que a doença se propaga.

de acordo com o MINISTÉRIO DA SAÚDE ${ }^{3}$ seria necessário imunizar, pelo menos, 90 a $95 \%$ da população para se interromper a transmissão do vírus do sarampo. Segundo a mesma fonte, no Brasil, as coberturas vacinais alcançadas em menores de um caso de idade, principal alvo do programa Nacional de Imunizações, oscilaram entre 56,4 (1980) e $80,1 \%$ (1984. Esses valores médios encobrem grandes variações regionais, que incluem áreas com coberturas vacinais extremamente baixas.

GIUGLIANI et alii ${ }^{5}$ mostram, através de um estudo realizado numa comunidade periférica de Porto Alegre, que apesar do grande desconhecimento da população com relação à causa, forma de contágio, manejo e prevenção do sarampo, $90 \%$ das crianças pesquisadas eram vacinadas contra a doença.

Acreditamos que um Programa Nacional eficiente de imunizações, aliado à conscientização dos profissionais da área de saúde, sobretudo relativos à educação em saúde, poderá trazer grande colaboração para a erradicação do sarampo.

Torna-se importante ressaltar, que a comunidade tem papel fundamental para esta meta.

Segundo ISMAIL ${ }^{6}$, o último caso de varíola no mundo acontecido há 11 anos - Ali Maow Maolin - é agora trabalhador de saúde na Somália, combatendo outra doença transmissível, o sarampo. Ali perdeu uma irmã devido às complicações desta doença e afïrma "Não quero que percam uma irmã ou uma filha antes de descobrirem demasiado tarde que a criança não precisava ter morrido ". 


\section{CONCLUSÕES E SUGESTÕES}

\subsection{Conclusões}

Dentro das características do presente estudo e dos enfoques nele considerados, acredita-se poder concluir que:

- O sarampo continua sendo uma doença endêmica na região de Londrina, tendo havido um surto epidémico no ano de 1987.

- O número de internações por sarampo foi maior no ano de 1987, ano em que foi maior o número de casos notificados.

A incidência do sarampo na região de Londrina foi maior na faixa etária entre 5 a 9 anos $(30,8 \%)$ e entre 1 a 4 anos $(27,9 \%)$.

- As instruções por sarampo ocorreram mais em crianças de baixa idade, ou seja, $35,5 \%$ pertenciam ao grupo etário entre 1 a 4 anos e $24,7 \%$ entre 5 a 11 meses.

- Cerca de 11,9\% dos casos de sarampo notificados na mesma região, necessitaram de internação.

- $O$ custo da vacina anti-sarampo na rede particular e 33,3 vezes maior que o custo da mesma vacina na rede pública.

- com o custo paciente-dia na Unidade de Doenças Transmissíveis do HURNP poder-se-ia imunizar 524 crianças na rede pública e 16 crianças na rede particular.

- Com o custo de uma hospitalização por sarampo num período de seis dias, $\mathrm{NCz} \$ 471,60$, seria possível imunizar 3.144 crianças na rede pública e 94 crianças na rede particular.

\subsection{Sugestões}

Com base nas informações obtidas na presente pesquisa e nas conclusões dela resultantes, julgamos conveniente propor as seguintes sugestões:

- Intensificar a vacinação anti-sarampo na região de Londrina.

- Conscientizar a comunidade, através da educação em saúde, da importância da vacinação anti-sarampo, assim como sobre a patologia e suas complicações e letalidade.

\section{REFERÊNCIAS BIBLIOGRÁFICAS}

1 ALMEIDA, M.M.M.B et alii. Fundamentos de alteraçōes do calendário e das normas de vacinação do estado de São Paulo. Rev. Bras. Med. 102 (4): 177-80, 1984.

2 BENENSON, A.S. Controle das doenças trantrisstveis no homem. 13 ed. Organização Panamericana de Saúde, Washington, 1983, no 442 p. 308-12.

3 BRASIL. Ministério da Saúde: Boletin Nacional de Epidemiologia. Sarampo no Brasil em 1988. Braślia, Divisāo Técnica de Divulgação, 1 (6), jun., 1988.

4 BRASIL. Ministério da Saúde: Boletim Nacional de Epidemiologia. Surto de Sarampo - Catolão - Goiás. Braşlia, Divisảo Técnica de Divulgação, 1 (๑), jun., 1988.

5 GIUGLIANI, E.R.J. et alii. Vacinação contra o sarampo e nivel de conhecimento sobre a doença numa periférica de Porto Alegre. Revista HCPA, 8 (2): 90-3, ago., 1988.

6 ISMAIL, E.A. Sobreviver à varfola para combater o sarampo. A Saude do Mundo, Genebra, jul., 1988.

7 LEONARDI, L. et alii. Estudo sobre o sarampo e aspectos básicos para a assistência de enfermagem. Laes, 6 (6): 5208, 1985.

8 MARTINS, R.M. Sarampo. In: FARHAT, C.K. Fundamentos e prática das inunizaçöes em cllnica médica e pediatria. Rio de. Janeiro: Atheneu, 1985 cap. 12, p. 235-62.

9 MITRE, H.P., MORAES, V.M.C. Sarampo. In: AMA TO NE TO, V. `BALDY, J.L. da S. Doenças transmisstveis. 3 ed., São Paulo: Sarvier, 1989. cap. 66, p. 773-81.

10 MORLEY, D. Sarampo. In: VERONESI, R. Doenças infecciosas e parasitarias. Rio de Janeiro: Guanabara Koogan, 1982, cap. 5, p. 25-9.

11 RISI Jr., J.B. apud MITRE, H.P., MORAES, V.M.C. de. Sarampo. In: AMAS TO NETO, V. BALDY, J.L. DA S. Doenças transmisstveis. 3 ed. São Paulo: Sarviar, 1989 , cap. 66, p. 773-81. 